|| ISSN(online): 2589-8698 || ISSN(print): 2589-868X || International Journal of Medical and Biomedical Studies

Available Online at www.ijmbs.info

PubMed (National Library of Medicine ID: 101738825)

Index Copernicus Value 2018: 75.71

Original Research Article

Volume 3, Issue 9; September: 2019; Page No. 170-172

A STUDY ON PREVALENCE OF DRY EYES IN A TERTIARY PRIVATE HOSPITAL

\title{
Dr. Rajani
}

Associate Professor, Department of Ophthalmology, Fathima Institute of Medical Sciences, Kadapa, AP.

Article Info: Received 24 August 2019; Accepted 22 September. 2019

DOI: https://doi.org/10.32553/ijmbs.v3i9.558

Corresponding author: Dr. Rajani

Conflict of interest: No conflict of interest.

\section{Abstract}

Introduction: Dry eye disease (DED) is a multifactorial ocular surface disease characterized by symptoms of discomfort, irritation, and visual disturbance. Dry eye disease (DED), either alone or in combination with other conditions, is a frequent cause of ocular irritation that leads the patients to seek ophthalmic care

Materials \& Methods: 150 study subjects were enrolled for the study. A cross-section hospital-based, observational study was conducted.

Results: Among the study subjects the maximum were from 61-70 year age group, followed by 51-60 year age group. Prevalence of DED was detected in $30 \%$.

Keywords: Dry eye, Kadapa, Meibomian gland dysfunction, Tear film breakup time

\section{Introduction:}

Dry Eye Disease is one of the most frequently diagnosed condition \& Tear substitutes are most often prescribed drops by Ophthalmologists. Dry eye disease (DED), either alone or in combination with other conditions, is a frequent cause of ocular irritation that leads the patients to seek ophthalmic care. Dry eye disease (DED) is a chronic ocular pathology and a major global health problem that manifests as a plethora of symptoms such as burning, photophobia, tearing, and grittiness. Patients with DED experience difficulties in daily routine activities thus compromising their quality of life. ${ }^{1}$

Information on DED is limited due lack of uniformity in its definition and the inability of any single diagnostic test or set of diagnostic tests to confirm or rule out the condition. Thus, there has been a shift towards symptom-based assessment as the key component of clinical diagnosis. ${ }^{2-6}$

Environmental factors, such as reduced humidity and increased wind, drafts, air conditioning, or heating may exacerbate the ocular discomfort. ${ }^{7}$

\section{Objectives:}

To study prevalence of dry eyes in a tertiary private hospital.

\section{MATERIALS AND METHODS}

The study was done in a tertiary care teaching hospital over a period of 2 years. The study period was from January 2017 to December 2017. Among the total out patients who attended the Ophthalmology department in Fathima Institute of Medical Sciences, 150 study subjects were enrolled using consecutive sampling.

Patients with ocular surface infections, foreign body, extensive ocular surface pathologies and those who had undergone an ocular surgery within 2 months were excluded from the study. All participants underwent a general ophthalmic assessment along with slit lamp examination and TBUT. TBUT was performed in all participants by a single observer. Tear film break-up time was used to assess the stability of the precorneal tear film.

Tear break up time ${ }^{8}$ : Fluorescein was applied to the ocular surface. The patient was asked to blink a few times before examination. Slit lamp biomicroscopy with a cobalt blue filter was used to investigate the tear film layer, and the interval from the last blink to the appearance of the first random dry spot on the cornea was noted. The test was repeated thrice and the mean value was calculated. Value of $<10 \mathrm{~s}$ was considered as indicative of tear film instability. ${ }^{9}$ 
Schirmer's test: Whatman filter paper was placed in the lower fornix at the lateral one-third of the lower lid margin. The extent of wetting of the strip was measured after $5 \mathrm{~min}$. Less than $5.5 \mathrm{~mm}$ of wetting was diagnostic of severe dry eye. ${ }^{10}$ Schirmer's test was done without anesthesia. To avoid the influence of conjunctiva-corneal staining on the Schirmer test, it was carried out at an interval of $10 \mathrm{~min}$ after the TBUT test.

Final grading of dry eye was done according to DEWS. $^{11}$

Grade 1-mild discomfort, TBUT variable, Schirmer's score variable

Grade 2-moderate discomfort, TBUT $<10 \mathrm{sec}$, Schirmer's score $<10 \mathrm{~mm}$

Grade 3-severe discomfort, TBUT $<5 \mathrm{sec}$, Schirmer's score $<5 \mathrm{~mm}$

Grade 4-disabling discomfort, TBUT immediate, Schirmer score $<2 \mathrm{~mm}$

(Grade 4 must have symptoms and signs)

\section{RESULTS:}

Table 1: Dry eye disease in relation to age distribution

\begin{tabular}{|l|l|l|l|}
\hline Age (years) & $\begin{array}{l}\text { Dry eye } \\
\text { present }\end{array}$ & $\begin{array}{l}\text { Dry eye } \\
\text { absent }\end{array}$ & $\begin{array}{l}\text { Total No of } \\
\text { patients }\end{array}$ \\
\hline $21-30$ & 5 & 15 & 20 \\
\hline $31-40$ & 12 & 25 & 37 \\
\hline $41-50$ & 4 & 18 & 22 \\
\hline $51-60$ & 10 & 20 & 30 \\
\hline $61-70$ & 14 & 27 & 41 \\
\hline Total & 45 & 105 & 150 \\
\hline
\end{tabular}

Among the study subjects the maximum were from 61-70 year age group, followed by 51-60 year age group. Prevalence of DED was detected in $30 \%$.

Table 2: Dry eye disease in relation to sex distribution

\begin{tabular}{|l|l|l|l|}
\hline Sex & $\begin{array}{l}\text { Dry eye } \\
\text { present }\end{array}$ & $\begin{array}{l}\text { Dry eye } \\
\text { absent }\end{array}$ & $\begin{array}{l}\text { Total No of } \\
\text { patients }\end{array}$ \\
\hline Females & 21 & 52 & 73 \\
\hline Males & 24 & 53 & 77 \\
\hline Total & $\mathbf{4 5}$ & $\mathbf{1 0 5}$ & $\mathbf{1 5 0}$ \\
\hline
\end{tabular}

Among the study subjects the maximum were males.

Table 3: Grading of dry eye according to Schirmer's test and tear film breakup time (TBUT)

\begin{tabular}{|l|l|l|}
\hline TBUT & Schirmer's (mm/5min) & TBUT (sec) \\
\hline Normal $(>15)$ & 12 & 2 \\
\hline Mild (10-15) & 15 & 24 \\
\hline Moderate (5-9) & 15 & 16 \\
\hline Severe $(<5)$ & 3 & 3 \\
\hline Total & $\mathbf{4 5}$ & $\mathbf{4 5}$ \\
\hline
\end{tabular}

Among the study subjects, Schirmer's test was normal among 12 subjects, mild and moderate in 15 subjects and severe in 3 study subjects. Among the study subjects, TBUT test was normal among 2 subjects, mild among 24 subjects, moderate in 16 subjects and severe in 3 study subjects.

Table 4: Severity of dry eye according to dry eye work shop (DEWS)

\begin{tabular}{|l|l|l|}
\hline TBUT & Number of patients (n) & Percentage \\
\hline Mild & 15 & 33.33 \\
\hline Moderate & 25 & 55.56 \\
\hline Severe & 5 & 11.11 \\
\hline Total & $\mathbf{4 5}$ & $\mathbf{1 0 0}$ \\
\hline
\end{tabular}

Among the study subjects based on DEWS classification, mild among 15 subjects, moderate in 25 subjects and severe in 5 study subjects.

\section{DISCUSSION}

The prevalence of dry eye in the present study was found to be $30 \%$. In a total of 150 patients, prevalence of dry eye was maximum $(66.37 \%)$ in the age group of 61 to 70 years, with mean age of $49.10 \pm 11.02$ years. Studies have reported the prevalence of dry eye to be varying from $5 \%$ to as high as $73.5 \% .{ }^{12,13}$ Another update from the international DEWS stated that the global prevalence of dry eye is about $17 \%$ while several other studies show a higher prevalence of approximately 30\% in people of Asian descent. ${ }^{14}$ An intact and efficient lipid layer in the tear film is required to prevent the evaporative loss of tear film. This lipid layer is thinner and less efficient in older subjects and particularly females. There is destabilization associated with significant changes in the tear lipid layer leading to less protection from evaporation in the older population. $^{15}$

Among the study subjects the maximum were from 61-70 year age group, followed by $51-60$ year age group. The prevalence of dry eye increased progressively with age. ${ }^{16}$ Suchi Shah and Harsha Jani showed in their study that maximum prevalence (32.5\%) of dry eye were in the age group of 51-60 years. ${ }^{17}$ Mohammed Azhar Chisti et al. showed that the highest prevalence of dry eye was in the age group of $41-50$ years (17.02\%) followed by $51-60$ years age group(15.56\%). ${ }^{18}$

Among the study subjects the maximum were males (53.33\%). The findings are more similar to studies in Uttarakhand. ${ }^{16}$ 
Exposure to excessive wind, sunlight or high temperature and air pollution were significantly related to dry eye. The hot and dry atmosphere aggravate symptoms of dry eye like grittiness, sandy and foreign body sensations which might compel the patient to seek advice. ${ }^{19}$

Among the study subjects, Schirmer's test was normal among 12 subjects, mild and moderate in 15 subjects and severe in 3 study subjects. Among the study subjects, TBUT test was normal among 2 subjects, mild among 24 subjects, moderate in 16 subjects and severe in 3 study subjects.

Among the study subjects based on DEWS classification, mild among 15 subjects, moderate in 25 subjects and severe in 5 study subjects.

This emphasizes the need for creating awareness among the study subjects to adopt protective measures during work. This might not altogether prevent the incidence of dry eye, but this is will help in delaying this condition and decreasing its severity. This also generates a need for regular screening for dry eye in this group of people who carry an immense burden of dry eye and are probably underreported due to their ignorance toward health. ${ }^{18}$

\section{CONCLUSION:}

In conclusion, the prevalence of the dry eye is $30 \%$ according to our Hospital based study.

\section{ACKNOWLEDGEMENTS}

We would like to thank all the study participants and the authors from where we have cited the references for publication of this article. Dry eye incidence increases with the age. The males were affected more than the females.

\section{REFERENCES}

1. Miljanović B, Dana R, Sullivan DA, Schaumberg DA. Impact of dry eye syndrome on vision-related quality of life. Am J Ophthalmol 2007;143:409-15.

2. Brewitt $H$, Sistani F. Dry Eye Disease: the scale of the problem. Surv Ophthalmol 2001; 45: S199-202.

3. Moss SE, Klein R, Klein BE. Prevalence of and risk factors for dry eye syndrome. Arch Ophthalmol 2000; 118: 1264-8.

4. Shimmura S, Shimazaki J, Tsubota K. Results of a population based questionnaire on the symptoms and lifestyles associated with dry eye. Cornea 1999; 18: 408-11.
5. Bandeen-Roche K, Munoz B, Tielsch JM, West SK, Schein OD. Self-reported assessment of dry eye in a population-based setting. Invest Ophthalmol Vis Sci 1997; 38: 2469-75.

6. McCarty CA, Bansal AK, Livingstone PM, Stanislavsky $\mathrm{YL}$, Taylor HR. The epidemiology of dry eye in Melbourne, Australia. Ophthalmology 1998; 105: 1114-9.

7. Dr. Lalit Verma. ALL INDIA OPHTHALMOLOGICAL SOCIETY. www.aios.org/cme/pppseries1.pdf

8. Titiyal JS, Falera RC, Kaur M, Sharma V, Sharma N. Prevalence and risk factors of dry eye disease in North India: Ocular surface disease index-based crosssectional hospital study. Indian J Ophthalmol 2018;66:207-11.

9. Lemp MA, Hamill JR Jr. Factors affecting tear film breakup in normal eyes. Arch Ophthalmol 1973;89:103-5.

10. Van Bijsterveld OP. Diagnostic tests in the Sicca syndrome. Arch Ophthalmol 1969;82:10-4.

11. Bhatnagar KR, Sapovadia A, Gupta D, Kumar P, Jasani $H$. Dry eye syndrome: A rising occupational hazard in tropical countries. Med J DY Patil Univ. 2014;7:138.

12. The epidemiology of dry eye disease: report of the Epidemiology Subcommittee of the International Dry Eye WorkShop (2007). Ocul Surf. 2007 Apr; 5(2):93107.

13. Uchino $M$, Dogru $M$, Yagi $Y$, Goto $E$, Tomita $M$, Kon $T$, Saiki M, Matsumoto Y, Uchino Y, Yokoi N, Kinoshita S, Tsubota KOptom Vis Sci. 2006 Nov; 83(11):797-802.

14. 6th International Conference on the Tear Film \&amp; Ocular Surface: basic science and clinical relevance (Florence, Italy, September 2010).

15. Maïssa C, Guillon M. Tear film dynamics and lipid layer characteristics--effect of age and gender. Cont Lens Anterior Eye. 2010 Aug; 33(4):176-82.

16. Baisoya $P$, Raj A, Bahadur $H$, Nagpal RC. The prevalence and clinical profile of dry eye in tertiary hospital based normal healthy population in Uttarakhand, India. Int J Community Med Public Health 2016;3:2521-6.

17. Basak SK, Pal PP, Basak S, Bandyopadhyay A, Choudhury S, Sar S. Prevalence of Dry Eye Diseases in hospital-based population in West Bengal, Eastern India. J Indian Med Assoc. 2012; 110: 789-94.

18. Shah S, Jani H. Prevalence and associated factors of dry eye: Our experience in patients above 40 years of age at a Tertiary Care Center. Oman J Ophthalmol. 2015;8(3):151-156.

19. Cynthia IT, Andrew FP, Koray G, Stephen CP. Tear meniscus dimensions in tear dysfunction and their correlation with clinical parameters. AmJ Ophthalmol. 2014;157:301-10. 